\title{
Diffusion Behaviours of Three Thioureido Imidazoline Corrosion Inhibitors in a Simulated Sediment Layer
}

\author{
Zhiwei Tie ${ }^{1}$, Wenwen Song ${ }^{2}$, Jingmao Zhao ${ }^{1,3, *}$ \\ ${ }^{1}$ College of Material Science and Engineering, Beijing University of Chemical Technology, Beijing \\ 100029, China \\ ${ }^{2}$ Research Institute of Oil-gas Engineering, Tarim Oilfield Company, Petrochina, Korla 841000, China \\ ${ }^{3}$ Beijing Key Laboratory of Electrochemical Process and Technology for Materials, Beijing 100029, \\ China \\ *E-mail: jingmaozhao@126.com
}

doi: $10.20964 / 2018.06 .72$

Received: 10 February 2018 / Accepted: 11 April 2018 / Published: 10 May 2018

\begin{abstract}
In the present work, the diffusion behaviours of three thioureido imidazoline inhibitors (SOIMS, SOIM and OIM) in a simulated sediment layer were investigated by ultraviolet-visible spectrophotometry (UV-vis) and potentiodynamic polarization in a simulation setup. The simulated sediment layer was characterized by SEM and mercury intrusion experiments. SEM observation shows that the sediment layer obtained in this experiment is relatively dense with no large pores. The mercury intrusion experiment was used to analyse the pore size distribution of the simulated deposition. UV-vis experiments show that the diffusion behaviours of corrosion inhibitors are related to their water solubility. The better the water solubility of the corrosion inhibitors, the stronger their ability to diffuse through the sediment layer. The UV-vis and potentiodynamic polarization results suggest that the three corrosion inhibitors can diffuse through the sediment layer as the diffusion time increases.
\end{abstract}

Keywords: Corrosion inhibitor; Diffusion; Sediment layer; Carbon steel; Potentiodynamic polarization

\section{$\underline{\text { FULL TEXT }}$}

(C) 2018 The Authors. Published by ESG (www.electrochemsci.org). This article is an open access article distributed under the terms and conditions of the Creative Commons Attribution license (http://creativecommons.org/licenses/by/4.0/). 